\title{
Perinatal bilateral testicular torsion: A rare emergency with review of literature
}

\author{
Amit Gupta', Akhil Kumar', Bhavesh Chadha', Megha Saroha² \\ ${ }^{1}$ Department of Surgery University College of Medical Sciences and Associated, ${ }^{2}$ Department of Pathology, University College of Medical \\ Sciences and Associated, Guru Teg Bahadur Hospital, New Delhi, India
}

\section{A B S T R A C T}

Perinatal bilateral testicular torsion is an extremely rare surgical emergency and is subject of debate among surgeons. Urgent surgical exploration and fixation of the other testis are the key points in the management.

Key words: Testicular Torsion, Neonatal, Perinatal

Access this article online

Website:

http://nepjol.info/index.php/AJMS

\section{INTRODUCTION}

Perinatal testicular torsion (PTT) is defined, somewhat arbitrarily, by some authors as testicular torsion to occur either prenatally or in the first 30 days of life. ${ }^{1,2}$ Testicular torsion was first described in 1840 by Delasiauve ${ }^{3}$ Despite over a century old pathology its clinical features, cause, risk factors and management is hounded by controversies, outcome of this condition is dismal. Management of PTT is controversial due to poor salvage rate \& risk of anaesthesia in new-borns. Hereby we are reporting one such case of bilateral PT'T along with review of literature and controversies surrounding it.

\section{CASE REPORT}

A 24 hours old newborn was referred with history of discoloration of scrotal skin \& enlarged scrotum. Neonate was full term born, by forceps delivery with breech presentation. At birth general condition was satisfactory with APGAR score of 9 and body weight of $2.4 \mathrm{~kg}$. Neonate was healthy with no feeding difficulty or systemic complaints. On examination scrotum was enlarged, firm, nontender with hyper pigmentation of skin \& reduced transillumination. Due to suspicion of testicular torsion immediately Doppler study was performed which showed enlarged mass bilaterally with absent blood flow \& fluid collection. Immediate surgical exploration was done, which revealed bilateral testicular torsion with gangrenous testes (Figure 1). Testes were non salvageable so bilateral orchidectomy was performed. Histopathology report confirmed gangrene of bilateral testes. Post operatively neonate performed well with uneventful stay in hospital. He was discharged after 3 days in good health.

\section{DISCUSSION}

Testicular torsion was first described by Delasiauve in 1840. ${ }^{3}$ First case of neonatal testicular torsion was reported in 1897 by Taylor. ${ }^{4}$ At that time its cause and importance

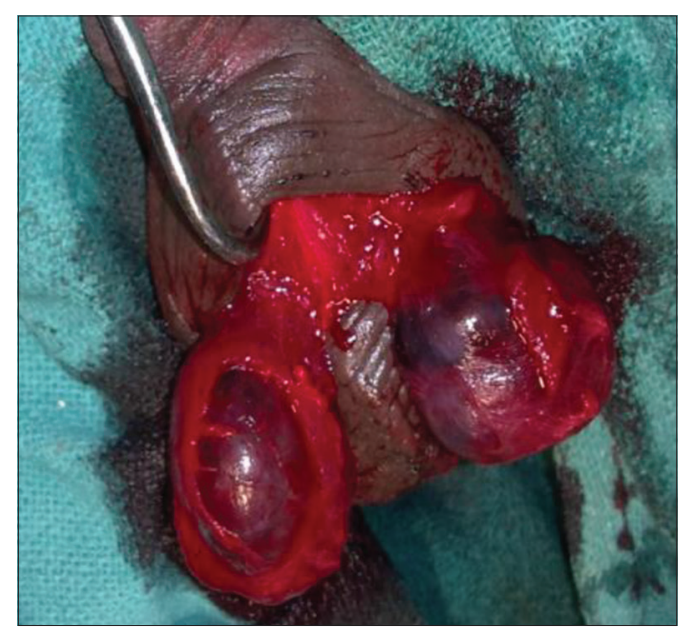

Figure 1: Intra-operative photograph showing bilateral torted gangrenous testis 
of early diagnosis and treatment was not recognized. Later in 1907, Rigby and Howard described it as vascular emergency and need for urgent diagnosis and treatment was emphasised. ${ }^{11}$ It was only by 1967 that bilateral PTT was first reported by Papadatos and Moutsouris. ${ }^{6}$ Since first description of PT'T till date nearly 268 cases have been reported in English literature ${ }^{5}$ of these, only 56 cases had bilateral testicular torsion. ${ }^{7}$ Testicular torsion is of two types prenatal i.e. occurring before or during birth, accounting for $72 \%$ of cases and postnatal i.e. occurring after birth within first 28 days of life, responsible for nearly $28 \%$ of cases of PTT. $^{2}$ It is usually extravaginal in about $92 \%$ of cases especially, if occurring early in neonatal life. ${ }^{8}$ It is due to fact that in early neonatal period tunica vaginalis is not yet secured to the gubernaculum and, therefore, the spermatic cord, as well as the tunica vaginalis, undergoes torsion as a unit.

Etiological factors or risk factors leading to PTT are ill defined. Factors associated with difficult labour or raised intra uterine pressure may be responsible for it. Vaginal delivery, prolonged labour, pre-eclampsia, gestational diabetes, twin pregnancy, a higher birth weight, breech presentation, overactive cremasteric reflex, presence of prenatal hydronephrosis are found in about half of patients. ${ }^{9}$ This suggests that foetal stress and/or mechanical factors during pregnancy or delivery may play a role in the pathogenesis of PT'T. However it is possible that foetal stress might actually be precipitated by PT'T and not actually cause of PT'T.

Diagnosis of PT'T itself poses a dilemma as in most of cases it is insidious with patient being asymptomatic, in contrary to torsion later in life. Clinical features are enlarged swollen scrotum, discoloration of scrotal skin, firmness with reduced transillumination. In some cases even these can be absent and only finding being non palpable testis. It has been noticed that earlier the torsion in intrauterine life lesser are the findings. Absence of pain is usual due to non development of pain pathway by that time. ${ }^{10}$ Pain and tenderness can be present in postnatal torsion. Presentation in such patients can be: ${ }^{1}$

1. An absent testis, if torsion occurs in prenatal period far from birth

2. Regular, firm, painless scrotal mass, smaller than the contra-lateral testis, with or without acute inflammatory signs, and does not transmit light. Seen when torsion occurs in prenatal period, weeks to several days before birth

3. A newborn will be born with acute inflammatory scrotal signs: a painful, enlarged, bluish or reddish hemiscrotum with an enlarged testis and a thickened tender cord: when torsion occurs in prenatal period very near to birth, few days to hours
4. If torsion occurs in postnatal period within the first month of life, the child will be born without any scrotal signs and the acute inflammatory signs will appear later.

High index of suspicion and good clinical examination is required. Delayed diagnoses with overt features or those diagnosed later by Doppler have already lost the survival battle. A somewhat firm testicle is pathognomonic of PTT.

Doppler study has high specificity for diagnosis. Drawbacks of using Doppler as diagnostic test are that time lost in study could be fatal for testis, reactive hypervascularity in cases with intermittent torsion $\&$ perfusion by collaterals can give false results.

In initial studies it was found that salvage rate was poor and risk of anaesthesia in young neonates was there, so more conservative approach with elective contralateral orchidopexy was employed. In later nineties it was found that risk of asynchronous P'T although small but disastrous, was there so management has now changed to immediate exploration, de-rotation and orchidopexy. Bilateral torsion is a true emergency and the management is straightforward immediate surgery. Threshold for performing bilateral testicular detorsion and fixation should be low and every effort should be made to leave even necrotic testes in place, as some testicular function may still be possible as suggested by Callewaert, ${ }^{12}$ but in our case both the testes very gangrenous and hence bilateral orchidectomy had to be performed.

Despite all efforts salvage rate are not satisfactory, varying from $5-22 \% .^{2,5,9}$ However it has been noted salvage rates are better in patients with postnatal torsion, upto $25 \%$. Also results are better if urgent exploration was protocol of management $(21.7 \%) .5,9$

\section{CONCLUSION}

Although PTT is quite rare \& possibility of salvaging the involved testicle is very low, it is hard to justify conservative approach to a condition resulting in such a devastating condition as anorchia. It is an abnormality which must be recognized in an urgent fashion if the testicle is to be salvaged. Hence, all paediatricians and emergency physicians should be aware of the clinical presentation of testicular torsion, thereby allowing rapid intervention and preservation of the testicle. Time should not be wasted in doing investigations because imaging studies have a limited role in preoperative management.

We describe a case of bilateral perinatal testicular torsion, discuss diagnosis and controversies on the management of perinatal testicular torsion. 


\section{REFERENCES}

1. Riaz-UI-haq M, Mahdi DA and Elhassan EU. Neonatal Testicular Torsion; a Review Article. Iran J Pediatr 2012;22 (3):281-289.

2. Das $S$ and Singer A. Controversies of perinatal torsion of the spermatic cord: a review, survey and recommendations. J Urol 1990;143:231-233.

3. Delasiauve LJF. Descente tardive du testicule gauche, prise pour une hernie étranglée. Rev Med Fr Etrang 1840;1:15-18.

4. Taylor MR. A case of testicle strangulated at birth: castration: recovery. BMJ 1897;1:458.

5. Nandi B and Murphy FL. Neonatal testicular torsion: a systematic literature review. Pediatric Surg Int 2011;27:1037-1040.

6. Papadatos $\mathrm{C}$ and Moutsouris $\mathrm{C}$. Bilateral testicular torsion in the newborn. Arch Surg 1967;71:249-251.
7. Roth CC, Mingin GC and Ortenberg J. Salvage of bilateral asynchronous perinatal testicular torsion. J Urol 2011;185:2464-2468.

8. Nariman $\mathrm{S}$ and Tabari AK. Perinatal testicular torsion: a case report. Arch Iranian Med 2005;8(4):321-322.

9. Kaye JD, Levitt SB, Friedman SC, Franco I, Gitlin J and Palmer LS. Neonatal torsion: a 14-year experience and proposed algorithm for management. J Urol 2008;179(6):2377-2383.

10. Yerkes EB, Robertson FM, Gitlin J, Kaefer M, Cain MP and Rink RC. Management of perinatal torsion: today, tomorrow or never? The journal of urology 2005;174:1579-1583.

11. Rigby $\mathrm{HM}$ and Howard RJ. Torsion of the testis. Lancet 1907;1:1415-1421.

12. Callewaert PR and Kerrebroeck PV. New insights into perinatal testicular torsion. Eur J Pediatr 2010;169:705-712.

Authors Contribution:

AG, AK \& BC - operated the case, collection of photographs; AG - compiled the case report; MS - Reviewed the manuscript.

Source of Support: Nil, Conflict of Interest: None declared. 